\title{
Robotic versus laparoscopic gastrectomy for gastric cancer: an umbrella review of systematic reviews and meta-analyses
}

\author{
Luigi Marano $^{1}\left[\right.$ D $\cdot$ Daniele Fusario $^{1}\left[\right.$ Vinno Savelli $^{1} \cdot$ Daniele Marrelli $^{1}\left[\right.$ Franco Roviello $^{1}$ (i)
}

Received: 21 October 2020 / Accepted: 19 April 2021 / Published online: 25 May 2021

(c) The Author(s) 2021

\begin{abstract}
An umbrella review was performed to summarize literature data and to investigate benefits and harm of robotic gastrectomy (RG) compared to laparoscopic (LG) approach. To overcome the intrinsic limitations of laparoscopy, the robotic approach is claimed to facilitate lymph-node dissection and complex reconstruction after gastrectomy, to assure oncologic safety also in advanced gastric cancer. A literature search was conducted in PubMed, Cochrane and Embase databases for all metaanalyses published up to December 2019. The search strategy was previously published in a protocol. We selected fourteen meta-analyses comparing outcomes between LG and RG with curative intent in patients with diagnosis of resectable gastric cancer. We highlight that RG has a longer operation time, inferior blood loss, reduction in hospital stay and a more rapid recovery of bowel function. In meta-analyses with statistical significance the number of nodes removed in RG is higher than LG and the distal margin of resection is higher. There is no difference in terms of total complication rate, mortality, morbidity, anastomotic leakage, anastomotic stenosis, intestinal obstruction and in conversion rate to open technique. The safety and efficacy of robotic gastrectomy are not clearly supported by strong evidence, suggesting that the outcomes reported for each surgical technique need to be interpreted with caution, in particular for the meta-analyses in which the heterogeneity is large. Certainly, robotic gastrectomy is associated with shorter time to oral intake, lesser intraoperative bleeding and longer operation time with an acceptable level of evidence. On the other hand, the data regarding other outcomes are insufficient as well as non-significant, from an evidence point of view, to draw any robust conclusion.
\end{abstract}

Keywords Adult surgery $\cdot$ Gastrointestinal tumours $\cdot$ Oncology $\cdot$ Systematic review $\cdot$ Robotic surgery

\section{Introduction}

Gastric cancer (GC) is the fifth most common malignant neoplasm and the third leading cause of cancer related deaths globally and for resectable gastric cancer (GC) patients the recommended surgical procedure is the standard gastrectomy with D2 lymphadenectomy [1]. the Japanese, Korean, Italian, German and British national guidelines recommend D2 procedure as the standard of surgical treatment with curative intent, as reported by the European Society for Medical Oncology (ESMO) guidelines, as well as the joint ESMO_European Society of Surgical Oncology

Luigi Marano

luigi.marano@unisi.it

1 Unit of General Surgery and Surgical Oncology, Department of Medicine, Surgery and Neurosciences, University of Siena, Strada delle Scotte, 4, 53100 Siena, Italy
(ESSO) - European Society of Radiotherapy and Oncology (ESTRO) guidelines [2].

During the last decades, minimally invasive surgery of the stomach has become increasingly employed worldwide. Laparoscopic gastrectomy (LG) has been routinely used for the treatment of GC, supported by strong evidence that $\mathrm{LG}$ is technically safe and leads to better short-term outcomes than conventional open gastrectomy for early stage gastric cancer [3-12]. However, diffusion of laparoscopic surgery is limited by technical difficulties regarding total gastrectomy procedure as well as D2 lymphadenectomy, that entails the removal of node stations along the celiac trunk, left gastric artery and hepatic pedicle $[13,14]$; these factors limit the execution of a correct D2 spleen-preserving laparoscopic gastrectomy (LG) for the treatment of advanced gastric cancer only to high-volume centres.

Since the first robot-assisted gastrectomy reported by Hashizume et al. in 2003 [15], robotic gastrectomy (RG) is claimed to facilitate complex reconstruction after 
gastrectomy and lymph node dissection, to assure oncologic safety also in advanced gastric cancer patients [16-18]. In current literature, many observational studies reported the effectiveness and safety of RG [19-23] and previous metaanalyses [24-26] highlighted a lower complication rate as well as bleeding in the robotic approach group when compared to the laparoscopic one.

Since several previous systematic reviews on the comparison of RG and LG are available and timely evidence is required to inform the scientific community, we believed a de novo systematic review was inappropriate, and, as reported in our published protocol [27], we performed a comprehensive umbrella review to collect and assess information from previous systematic reviews that have compared the laparoscopic with robotic gastrectomy.

Umbrella reviews are syntheses of existing systematic reviews and/or meta-analyses providing an ideal method to comprehensively review the evidence base and to explore the contradictory findings of previous reviews [28].

The aim of this review is to investigate the benefits and harm of robotic gastrectomy compared with laparoscopic approach searching between the findings of high-quality systematic reviews, to give surgeons and policymakers a comprehensive overview of the depth and strength of the scientific evidence to evaluate the feasibility of the robotic gastrectomy for gastric cancer.

\section{Methods and analysis}

This umbrella review was designed using the methodology guidelines for umbrella reviews provided by the Joanna Briggs Institute [28]. As well, we followed the Preferred Reporting Items for Systematic review and Meta-Analyses (PRISMA) guidelines [29] (Appendix 1). The protocol has been registered with PROSPERO (no. CRD42019139906) and has been published [27]. The review was performed following the protocol without deviation.

\section{Search strategy, study selection and data collection}

We searched for systematic review and meta-analysis comparing the outcomes of robotic gastrectomy (RG) and laparoscopic gastrectomy (LG) in patients with gastric cancer. A literature search was conducted in PubMed, Cochrane and Embase databases for all articles published up to December 2019. The "related article" function from PubMed will be used to further identify potential articles that were eligible for inclusion in the review. The bibliography of all selected articles will be hand searched to identify additional articles that met our inclusion criteria [27].

Two independent reviewers (LM and DF) had screen titles, abstract and full-text records in duplicate. Data were extracted by two authors (LM and DF), who independently reviewed and screened all eligible studies for content according to the inclusion criteria indicated in the protocol. We extracted only data pertaining to the comparison between RG and LG. The quality of the included studies was assessed using the appropriate AMSTAR (A Measurement Tool to Assess Systematic Reviews) [30] checklist by the two reviewers: of the included studies only one had scored 6 points on the AMSTAR check list, the others had scored 7 or more points (Table 1 ).

\section{Statistical analyses}

For each meta-analysis, we estimated the summary effect size and its $95 \% \mathrm{CI}$ using random-effects models. For the largest study of each meta-analysis, we estimated the SE of the effect size and we examined whether the SE was less than 0.1 . In a study with SE of less than 0.1 , the difference between the effect estimate and the upper or lower $95 \%$ confidence interval is less than 0.2 (i.e., this uncertainty is less than what is considered a small effect size). In case of meta-analyses with continuous data, the effect estimate was transformed to an odds ratio with an established formula [31]. Between-study heterogeneity was assessed via the $I^{2}$ metric. $I^{2}$ ranges between 0 and $100 \%$ and is the ratio of between-study variance over the sum of the within- and between-study variances. Values exceeding 50\% are usually considered to represent large heterogeneity.

We evaluated whether there was evidence for small-study effects using the Egger $p$ test [32] A P value less than 0.1 with more conservative effect in larger studies judged to be evidence for small-study effects. We applied the excess statistical significance test, which evaluates whether the observed number of studies with nominally statistically significant results.

Finally, we identified outcomes that had the strongest statistical support for association and no signals of high heterogeneity or bias. Specifically, we used the following categories:

- convincing (class I) when number of cases $>1000$, $p<10-6, \mathrm{I} 2<50 \%, 95 \%$ prediction interval excluding the null, no small-study effects and no excess significance bias:

- highly suggestive (class II) when number of cases $>1000$, $p<10-6$, largest study with a statistically significant effect and class I criteria not met;

- suggestive (class III) when number of cases $>1000$, $p<10-3$ and class I-II criteria not met;

- weak (class IV) when $p<0.05$ and class I-III criteria not met;

- non-significant when $p>0.05$. 


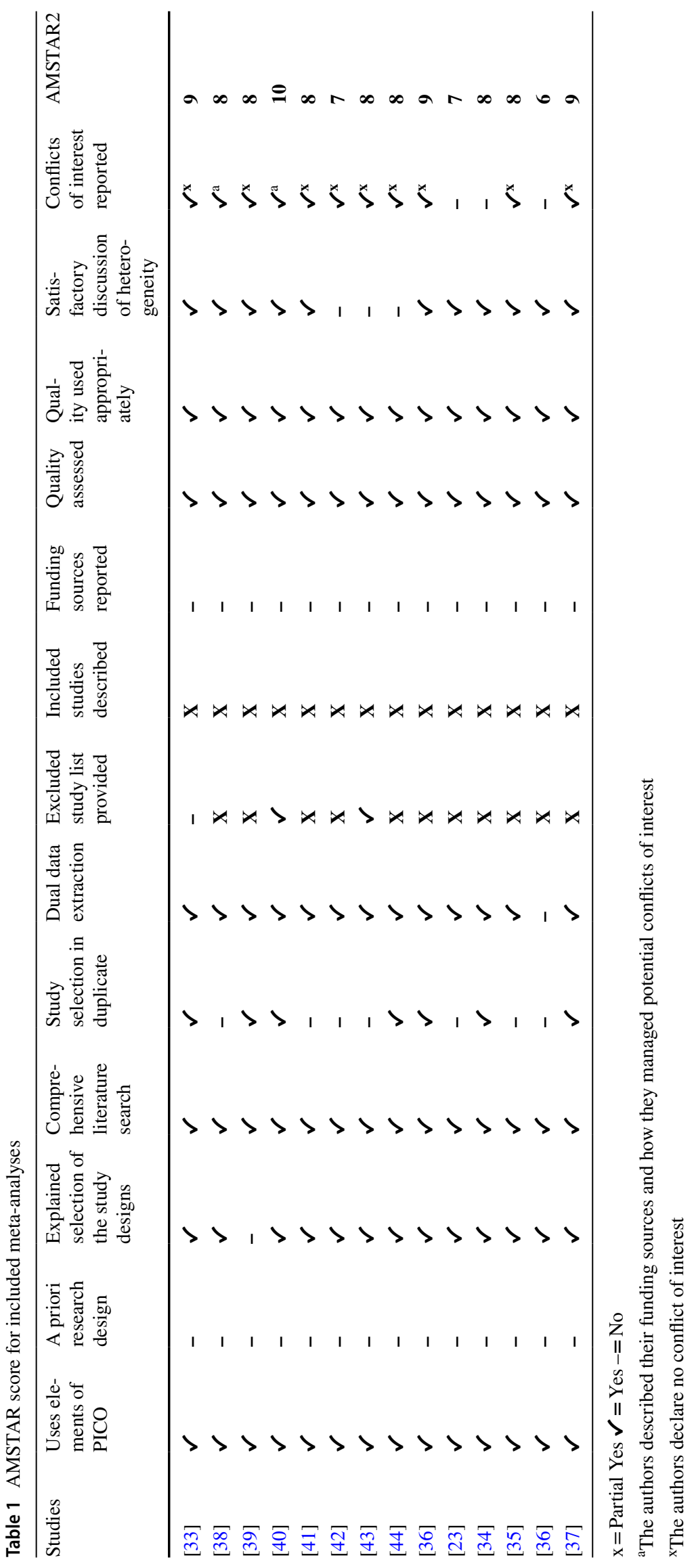


The statistical analysis and the power calculations were done with STATA version 12.0.

\section{Results}

\section{Search strategy}

One hundred and fifty-six records were found from our literature search. (Appendix 2). Of these, 137 were excluded after a rapid screening of title and abstract. The other five articles were excluded after full-text screening. In total, we selected 14 meta-analyses (Table 2) The full list of the included studies is available in Appendix 3.

\section{Review characteristics}

All the 14 included meta-analyses [23, 33-45] compare short-term outcomes between laparoscopic and robotic total/ subtotal gastrectomy with curative intent in adult patients with diagnosis of resectable gastric cancer (Table 3).

Every study compares the short-term outcomes of robotic surgery with the laparoscopic approach in terms of operation time, blood loss, number of harvested lymph nodes and length of hospital stay. Eleven studies [23, 34-38, 40-42, 44, 45] compare the total complication rate after gastrectomy and, of these, three $[23,37,39]$ analyse the conversion rate to open technique, five $[38,39,41,43,44]$ the anastomotic leakage rate, three $[38,39,41]$ the anastomotic stenosis rate, two [38, 39] intestinal occlusions, just one [38] the postoperatory bleeding.
Seven [23, 33, 35, 37-39, 43] meta-analyses consider the post-operatory mortality rate, three $[33,39,43]$ the morbidity rate.

Only three $[34,35,39]$ studies report the time to the first oral intake and five [23, 34, 35, 37, 39] the first time to flatus.

The oncological outcomes in terms of total retrieved lymph nodes were compared in selected meta-analyses. Interestingly, nine [23, 35-39, 41, 42, 44] studies report the proximal and distal margin of resection. Only one meta-analysis [37] reports the 3-year overall survival and the 3-year disease-free survival and another one [35] reports the recurrence free survival.

\section{Summary of outcomes}

In the following paragraph, we describe the findings from the included meta-analyses. In each review we found data for the primary outcomes: operation time, intraoperative bleeding, length of stay and number of harvested lymph-nodes. Along the way, we also analysed other outcomes findings in the selected studies as conversion rate, mortality rate, morbidity, total complication rate, anastomotic leakage, anastomotic stenosis, intestinal obstruction, proximal and distal margin, time to first flatus and for oral intake.

For each review we extracted, for continuous variables, the weighted mean difference (WMD), the $95 \%$ confidence interval $(95 \% \mathrm{CI})$ and the heterogeneity. For the discrete variables, we reported odd ratio (OR), the $95 \%$ confidence interval and the heterogeneity (Table 4).

\begin{tabular}{llllllll}
\hline Studies & Design & \multicolumn{2}{l}{ Continent (if specifi- } & N. participants & RG & LG & N. studies \\
& & \multicolumn{2}{l}{ cated country) } & & & \\
\hline$[39]$ & Meta-analysis & Asia & Europe (Italy) & 918 & 268 & 650 & 3 \\
{$[38]$} & Meta-analysis & Asia & Europe (Italy) & 2235 & 762 & 1473 & 7 \\
{$[39]$} & Meta-analysis & Asia & Europe (Italy) & 2495 & 736 & 1759 & 9 \\
{$[40]$} & Meta-analysis & Asia & Europe (Italy) & 1249 & 404 & 845 & 6 \\
{$[41]$} & Meta-analysis & Asia & Europe (Italy) & 1870 & 634 & 1236 & 8 \\
{$[42]$} & Meta-analysis & Asia & Europe (Italy) & 1875 & 506 & 1369 & 8 \\
{$[43]$} & Meta-analysis & Asia & Europe (Italy) & 3204 & 997 & 2207 & 11 \\
{$[44]$} & Meta-analysis & Asia & & 1796 & 551 & 1245 & 5 \\
{$[36]$} & Meta-analysis & Asia & & 562 & 165 & 397 & 3 \\
{$[23]$} & Meta-analysis & Asia & & 3580 & 1096 & 2484 & 12 \\
{$[34]$} & Meta-analysis & Asia & Europe (Italy) & 3503 & 993 & 2510 & 11 \\
{$[35]$} & Meta-analysis & Asia & Europe (Italy) & 5953 & 1830 & 4123 & 19 \\
{$[36]$} & Meta-analysis & Asia & Europe (Italy) & 3744 & 1134 & 2610 & 12 \\
{$[37]$} & Meta-analysis & Asia & Europe (Italy) & 4576 & 1517 & 3059 & 16 \\
\hline
\end{tabular}

Green are the meta-analyses that compares RG to LG and to Open Gastrectomy 
Updates in Surgery (2021) 73:1673-1689

1677

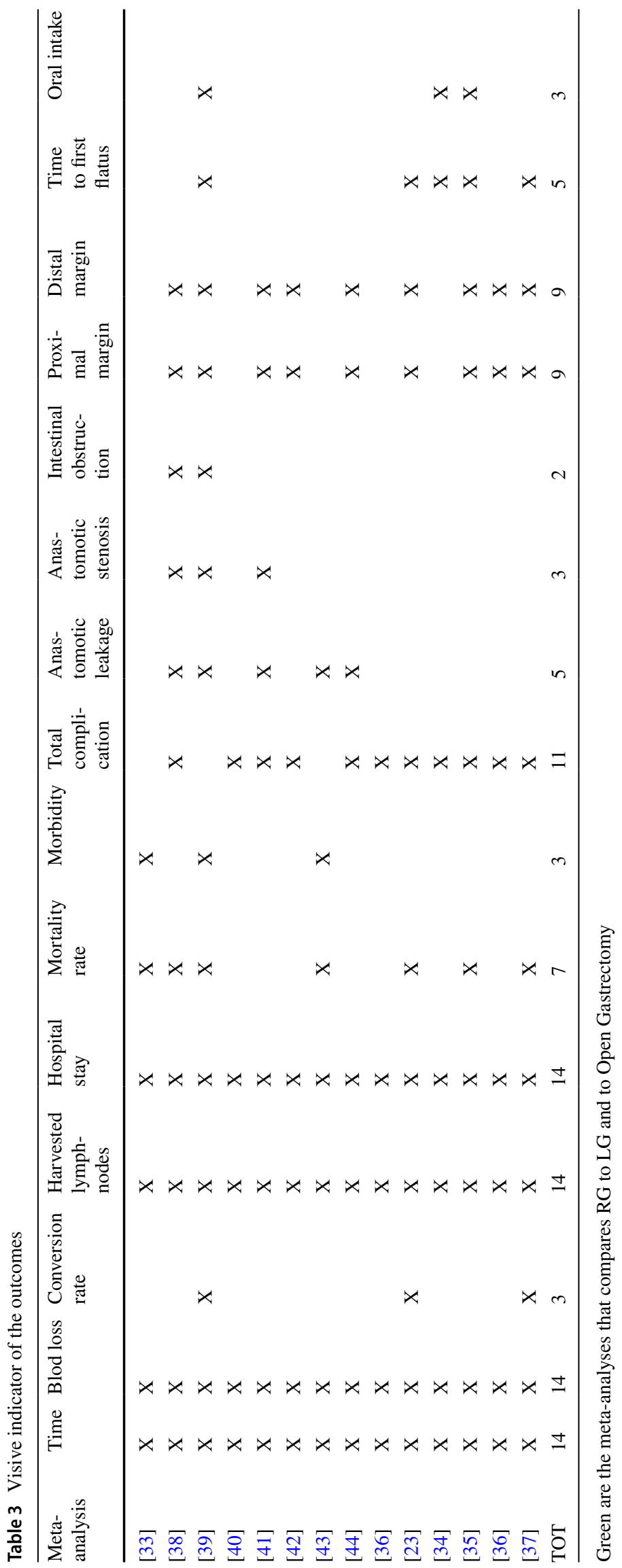

Springer 
Table 4 Outcomes

\begin{tabular}{|c|c|c|c|c|c|c|c|c|c|}
\hline \multicolumn{3}{|c|}{ Operation time (minutes) } & \multirow[b]{2}{*}{ RG } & \multirow[b]{2}{*}{ LG } & \multirow[b]{2}{*}{ WMD } & \multirow[b]{2}{*}{$95 \% \mathrm{CI}$} & & \multirow[b]{2}{*}{$p$ value } & \multirow[b]{2}{*}{$I^{2}(\%)$} \\
\hline & $N$ & N. of patients & & & & & & & \\
\hline [33] & 3 & 918 & 268 & 650 & 68.77 & 35.09 & 102.45 & $P<0.0001$ & 85 \\
\hline [38] & 6 & 2132 & 723 & 1409 & 50 & 30.07 & 69.93 & $P=0.00$ & 88 \\
\hline [39] & 7 & 2242 & 667 & 1575 & 48.64 & 29.79 & 67.5 & $P<0.0001$ & 87 \\
\hline [40] & 6 & 1214 & 373 & 841 & 63.7 & 44.22 & 83.17 & $P<0.00001$ & 74 \\
\hline [41] & 8 & 1870 & 643 & 1236 & 61.99 & 43.12 & 80.86 & $<0.001$ & 85 \\
\hline [42] & 7 & 1048 & 270 & 778 & 48.46 & 29.49 & 67.43 & $P=0.000$ & 86.6 \\
\hline [43] & 8 & 2859 & 898 & 1961 & 57.15 & 42.26 & 72.05 & $P<0.00001$ & 88 \\
\hline [44] & 5 & 1796 & 551 & 1245 & 42.9 & 2087 & 64.92 & $P=0.0001$ & 82 \\
\hline [36] & 3 & 562 & 165 & 397 & 21.49 & 12.48 & 30.5 & $P<0.00001$ & 57 \\
\hline [23] & 12 & 3580 & 1096 & 2484 & 42.437 & 31.82 & 53.053 & $P<0.0001$ & 89.7 \\
\hline [34] & 9 & 3250 & 924 & 2326 & 53.48 & 38.84 & 68.12 & $P=0.00$ & 87.1 \\
\hline [35] & 19 & 5953 & 1830 & 4123 & 49.05 & 39.91 & 58.18 & $P<0.01$ & 88 \\
\hline [36] & 11 & 3374 & 949 & 2425 & 42 & 28.11 & 55.89 & $P<0.00001$ & 88 \\
\hline [37] & 16 & 4586 & 1517 & 3069 & 57.98 & 42.96 & 73 & $P<0.00001$ & 94 \\
\hline \multicolumn{10}{|c|}{ Blood loss (ML) } \\
\hline & $N$ & n. of patients & RG & LG & WMD & $95 \% \mathrm{CI}$ & & $p$ value & $I^{2}(\%)$ \\
\hline [33] & 3 & 918 & 268 & 650 & -41.88 & -71.62 & -12.14 & $P=0.006$ & 73 \\
\hline [38] & 6 & 2031 & 687 & 1344 & -46.97 & -87.83 & -6.12 & $P=0.02$ & 98 \\
\hline [39] & 6 & 2123 & 613 & 1510 & -33.56 & -59.82 & -7.3 & $P=0.01$ & 93 \\
\hline [40] & 5 & 1113 & 337 & 776 & -35.53 & -66.98 & -4.09 & $P=0.03$ & 75 \\
\hline [41] & 8 & 1870 & 634 & 1236 & -6.08 & -25.73 & 13.58 & $P=0.54$ & 83 \\
\hline [42] & 6 & 666 & 170 & 496 & -38.43 & -67.55 & -9.3 & $P=0.01$ & 93.3 \\
\hline [43] & 7 & 2758 & 862 & 1896 & -28.59 & -56.57 & -0.62 & $P=0.05$ & 92 \\
\hline [44] & 4 & 1695 & 515 & 1180 & -16.07 & -32.78 & 0.64 & $P=0.006$ & 75 \\
\hline [36] & 3 & 562 & 165 & 397 & -16.6 & -61.31 & 28.11 & $P=0.47$ & 94 \\
\hline [23] & 11 & 1028 & 2416 & 3444 & -29.855 & -46.236 & -13.474 & $P<0.0001$ & 94.3 \\
\hline [34] & 8 & 3149 & 888 & 2261 & -36.5 & -61.39 & -11.61 & $P=0.00$ & 92.1 \\
\hline [35] & 18 & 5817 & 1762 & 4055 & -24.38 & -36.43 & -12.32 & $P<0.01$ & 93 \\
\hline [36] & 11 & 3374 & 949 & 2425 & -23.68 & -42.25 & -5.1 & $P=0.01$ & 91 \\
\hline [37] & 16 & 4586 & 1517 & 3069 & -23.71 & -40.1 & -7.32 & $P=0.005$ & 89 \\
\hline \multicolumn{10}{|c|}{ Harvested lymphnodes } \\
\hline & $N$ & n. of patients & RG & LG & WMD & $95 \% \mathrm{CI}$ & & $p$ value & $I^{2}(\%)$ \\
\hline [33] & 3 & 918 & 268 & 650 & 0.71 & -6.78 & 5.36 & $P=0.82$ & 87 \\
\hline [38] & 6 & 1853 & 662 & 1191 & 1.61 & -1.17 & 4.39 & $P=0.26$ & 85 \\
\hline [39] & 7 & 1963 & 606 & 1357 & 1.28 & -2.19 & 4.76 & $P=0.47$ & 78 \\
\hline [40] & 6 & 1214 & 373 & 841 & 0.5 & -3.3 & 4.3 & $P=0.80$ & 80 \\
\hline [41] & 8 & 1870 & 634 & 1236 & -0.25 & -3.72 & 3.22 & $P=0.89$ & 81 \\
\hline [42] & 7 & 1493 & 406 & 1087 & 1.06 & -2.33 & 4.45 & $P=0.54$ & 74.1 \\
\hline [43] & 8 & 2580 & 837 & 1743 & 0.63 & -2.24 & -3.51 & $P=0.67$ & 78 \\
\hline [44] & 5 & 1796 & 551 & 1245 & 2.45 & 0.94 & 3.95 & $P=0.001$ & 0 \\
\hline [36] & 2 & 200 & 85 & 115 & -0.23 & -3.8 & 3.35 & $P=0.9$ & 0 \\
\hline [23] & 11 & 2823 & 951 & 1872 & 2.11 & 0.63 & 3.59 & $P=0.005$ & 67.1 \\
\hline [34] & 8 & 2144 & 627 & 1517 & 1.49 & -1.74 & 4.72 & $P=0.00$ & 74.3 \\
\hline [35] & 17 & 4814 & 1585 & 3229 & 1.44 & -0.37 & 3.26 & $P=0.12$ & 86 \\
\hline [36] & 10 & 2998 & 849 & 2143 & 0.91 & -1.16 & 2.99 & $P=0.39$ & 70 \\
\hline [37] & 14 & 3434 & 1269 & 2165 & 1.81 & 0 & 3.62 & $P=0.05$ & 74 \\
\hline
\end{tabular}


Table 4 (continued)

Hospital stay (days)

\begin{tabular}{lllllllccc}
\hline & $n$ & n. of patients & RG & LG & WMD & 95\%CI & & $p$ value & $I^{2}(\%)$ \\
\hline$[33]$ & 3 & 918 & 268 & 650 & -0.54 & -1.87 & 0.79 & $P=0.42$ \\
\hline$[38]$ & 5 & 2011 & 685 & 1326 & -0.5 & -1.07 & -0.08 & $P=0.09$ \\
{$[39]$} & 7 & 2242 & 667 & 1575 & -1.16 & -2.42 & 0.1 & $P<0.00001$ & 76 \\
{$[40]$} & 6 & 1111 & 334 & 777 & -0.43 & -1.46 & 0.61 & $P=0.42$ & 87 \\
{$[41]$} & 8 & 1870 & 634 & 1236 & -0.6 & -1.39 & 0.2 & $P=014$ & 56 \\
{$[42]$} & 6 & 666 & 170 & 496 & -0.1 & -2.57 & 0.56 & $P=0.209$ & 80.6 \\
{$[43]$} & 7 & 2832 & 882 & 1950 & -0.16 & -0.87 & -0.55 & $P=0.65$ \\
{$[44]$} & 4 & 1675 & 513 & 1162 & -1.98 & -3.66 & -0.3 & $P=0.002$ \\
{$[36]$} & 3 & 562 & 165 & 397 & 0.19 & -0.91 & 1.3 & $P=0.74$ & 0 \\
{$[23]$} & 10 & 3345 & 1008 & 2337 & -0.465 & -0.741 & -0.19 & $P=0.001$ & 20.3 \\
{$[34]$} & 9 & 3250 & 924 & 2326 & -1.11 & -2.28 & 0.06 & $P=0.00$ & 73.1 \\
{$[35]$} & 19 & 5953 & 1830 & 4123 & -0.35 & -0.95 & 0.25 & $P=0.25$ & 82 \\
{$[36]$} & 11 & 3374 & 949 & 2425 & -0.65 & -1.53 & 0.23 & $P=0.15$ & 84 \\
{$[37]$} & 14 & 4345 & 1438 & 2907 & -0.49 & -0.99 & 0.02 & $P=0.06$ & 45 \\
\hline
\end{tabular}

Total complications

\begin{tabular}{|c|c|c|c|c|c|c|c|c|c|}
\hline & $n$ & n. of patients & RG & LG & OR & $95 \% \mathrm{CI}$ & & $p$ value & $I^{2}(\%)$ \\
\hline [38] & 7 & 2235 & 762 & 1473 & 1.07 & 0.82 & 1.4 & $P=0.61$ & 0 \\
\hline [40] & 6 & 1220 & 373 & 847 & 0.87 & 0.57 & 1.28 & $P=0.69$ & 0 \\
\hline [41] & 8 & 1870 & 634 & 1236 & 1.12 & 0.83 & 1.52 & $P=0.44$ & 0 \\
\hline [42] & 8 & 1875 & 506 & 1369 & 0.95 & 0.7 & 1.28 & $P=0.713$ & 0 \\
\hline [44] & 5 & 1796 & 551 & 1245 & 1.05 & 0.77 & 1.44 & $P=0.76$ & 0 \\
\hline [36] & 3 & 552 & 165 & 397 & 1.37 & 0.81 & 2.3 & $P=0.24$ & 0 \\
\hline [23] & 12 & 3580 & 1096 & 2484 & 1.02 & 0.78 & 1.32 & $P=0.897$ & 0 \\
\hline [34] & 11 & 3503 & 993 & 2510 & 1.02 & 0.81 & 1.27 & $P=0.8$ & 0 \\
\hline [35] & 19 & 5953 & 1830 & 4123 & 1.05 & 0.88 & 1.26 & $P=0.56$ & 0 \\
\hline [36] & 12 & 3744 & 1134 & 2610 & 1.12 & 0.89 & 1.41 & $P=0.33$ & 0 \\
\hline [37] & 14 & 4426 & 1487 & 2939 & 1.05 & 0.86 & 1.28 & $P=0.65$ & 2 \\
\hline \multicolumn{10}{|c|}{ Proximal margins (CM) } \\
\hline & $n$ & n. of patients & RG & LG & WMD & $95 \% \mathrm{CI}$ & & $p$ value & $I^{2}(\%)$ \\
\hline [38] & 3 & 389 & 171 & 218 & 0.31 & 0.18 & 0.8 & $P=0.22$ & 0 \\
\hline [39] & 3 & 1519 & 510 & 1009 & 0.11 & -0.17 & 0.39 & $P=0.42$ & 0 \\
\hline [41] & 5 & 1674 & 561 & 1113 & -0.06 & -0.32 & 0.19 & $P=0.10$ & 49 \\
\hline [42] & 3 & 1049 & 310 & 739 & 0.1 & -0.25 & 0.45 & $P=0.56$ & 0 \\
\hline [44] & 3 & 1519 & 510 & 1009 & 0.11 & -0.17 & 0.4 & $P=0.42$ & 0 \\
\hline [23] & 5 & 1067 & 374 & 693 & -0.104 & -0.307 & 0.099 & $P=0.314$ & 0 \\
\hline [35] & 9 & 3030 & 2006 & 1024 & 0.14 & -0.07 & 0.36 & $P=0.18$ & 26 \\
\hline [36] & 5 & 2456 & 723 & 1733 & 0.1 & -0.08 & 0.28 & $P=0.26$ & 4 \\
\hline [37] & 6 & 615 & N.D & N.D & 0.34 & -0.12 & 0.81 & $P=0.15$ & 0 \\
\hline \multicolumn{10}{|c|}{ Distal margins $(\mathrm{CM})$} \\
\hline & $n$ & n. of patients & RG & LG & WMD & $95 \% \mathrm{CI}$ & & $p$ value & $I^{2}(\%)$ \\
\hline [38] & 3 & 389 & 171 & 218 & -0.28 & -0.8 & -0.23 & $P=0.28$ & 0 \\
\hline [39] & 3 & 1519 & 510 & 1009 & 1.13 & 0.67 & 1.6 & $P<0.00001$ & 0 \\
\hline [41] & 5 & 1674 & 561 & 1113 & -1.14 & -1.55 & -0.72 & $P<0.01$ & 0 \\
\hline [42] & 3 & 1049 & 310 & 739 & 1.04 & 0.46 & 1.62 & $P=0.001$ & 0 \\
\hline [44] & 3 & 1519 & 510 & 1009 & 1.13 & 0.67 & 1.6 & $P<0.00001$ & 0 \\
\hline
\end{tabular}


Table 4 (continued)

Distal margins (CM)

\begin{tabular}{|c|c|c|c|c|c|c|c|c|c|}
\hline & $n$ & n. of patients & $\mathrm{RG}$ & LG & WMD & $95 \% \mathrm{CI}$ & & $p$ value & $I^{2}(\%)$ \\
\hline [23] & 5 & 1067 & 374 & 693 & -0.176 & -0.413 & 0.062 & $P=0.147$ & 0.278 \\
\hline [35] & 8 & 2921 & 973 & 1948 & -0.09 & -0.65 & 0.46 & $P=0.74$ & 81 \\
\hline [36] & 10 & 2456 & 723 & 1733 & 0.18 & -0.67 & 1.03 & $P=0.68$ & 68 \\
\hline [37] & 5 & 502 & N.D & N.D & 0.73 & -0.47 & 1.93 & $P=0.23$ & 64 \\
\hline \multicolumn{10}{|c|}{ Mortality } \\
\hline & $n$ & n. of patients & RG & LG & OR & $95 \% \mathrm{CI}$ & & $p$ value & $I^{2}(\%)$ \\
\hline [33] & 3 & 918 & 268 & 650 & 1.8 & 0.3 & 10.98 & $P=0.52$ & 0 \\
\hline [38] & 3 & 1464 & 491 & 973 & 1.59 & 0.42 & 5.94 & $P=0.49$ & 0 \\
\hline [39] & 8 & 2374 & 698 & 1676 & 1.66 & 0.44 & 6.24 & $P=0.45$ & 0 \\
\hline [43] & 5 & 2730 & 849 & 1881 & 1.36 & 0.38 & 4.88 & $P=0.63$ & 0 \\
\hline [23] & 3 & 1555 & 389 & 1166 & 0.61 & 0.12 & 3.1 & $P=0.9$ & 0 \\
\hline [35] & 7 & 2951 & 838 & 2131 & 1.62 & 0.62 & 4.2 & $P=0.32$ & 0 \\
\hline [37] & 14 & 2895 & 808 & 2087 & 1.35 & 0.6 & 4.14 & $P=0.56$ & 0 \\
\hline
\end{tabular}

Morbidity

\begin{tabular}{|c|c|c|c|c|c|c|c|c|c|}
\hline & $n$ & n. of patients & RG & LG & OR & $95 \% \mathrm{CI}$ & & $p$ value & $I^{2}(\%)$ \\
\hline [33] & 3 & 918 & 268 & 650 & 0.74 & 0.47 & 1.16 & $P=0.19$ & 0 \\
\hline [39] & 9 & 2495 & 736 & 1759 & 1.13 & 0.86 & 1.47 & $P=0.38$ & 0 \\
\hline [43] & 5 & 2730 & 849 & 1881 & 1.36 & 0.38 & 4.88 & $P=0.63$ & 0 \\
\hline \multicolumn{10}{|c|}{ Anastomotic leakage } \\
\hline & $n$ & n. of patients & RG & LG & OR & $95 \% \mathrm{CI}$ & & $p$ value & $I^{2}(\%)$ \\
\hline [38] & 6 & 2171 & 746 & 1425 & 1.61 & 0.92 & 2.64 & $P=0.05$ & 0 \\
\hline [39] & 8 & 2245 & 711 & 1534 & 1.06 & 0.6 & 1.89 & $P=0.83$ & 0 \\
\hline [41] & 8 & 1870 & 634 & 1236 & 1.06 & 0.57 & 1.94 & $P=0.86$ & 0 \\
\hline [43] & 5 & 2730 & 849 & 1881 & 1.16 & 0.68 & 1.96 & $P=0.59$ & 0 \\
\hline [44] & 3 & 1519 & 510 & 1009 & 0.98 & 0.51 & 1.9 & $P=0.95$ & 0 \\
\hline
\end{tabular}

Anastomotic stenosis

\begin{tabular}{llllllllll}
\hline & $n$ & n. of patients & RG & LG & OR & 95\%CI & & $p$ value & $I^{2}(\%)$ \\
\hline$[38]$ & 4 & 874 & 310 & 564 & 0.8 & 0.24 & 2.64 & $P=0.72$ \\
{$[39]$} & 7 & 948 & 275 & 673 & 0.67 & 0.18 & 2.5 & $P=0.55$ \\
{$[41]$} & 8 & 1870 & 634 & 1236 & 0.9 & 0.29 & 2.77 & $P=0.85$ & 0 \\
\hline
\end{tabular}

Intestinal obstruction

\begin{tabular}{|c|c|c|c|c|c|c|c|c|c|}
\hline & $n$ & n. of patients & RG & LG & OR & $95 \% \mathrm{CI}$ & & $p$ value & $I^{2}(\%)$ \\
\hline [38] & 4 & 1949 & 672 & 1277 & 1.38 & 0.55 & 3.46 & $P=0.48$ & 0 \\
\hline [39] & 7 & 2095 & 681 & 1414 & 1.64 & 0.43 & 2.53 & $P=0.92$ & 0 \\
\hline
\end{tabular}

Time to first flatus (days)

\begin{tabular}{|c|c|c|c|c|c|c|c|c|c|}
\hline & $n$ & n. of patients & RG & LG & WMD & $95 \% \mathrm{CI}$ & & $p$ value & $I^{2}(\%)$ \\
\hline [39] & 2 & 128 & 52 & 76 & -0.44 & -1.15 & 0.27 & $P=0.22$ & 0 \\
\hline [23] & 5 & 1174 & 444 & 730 & -0.26 & -0.38 & -0.14 & $P<0.0001$ & 0 \\
\hline [34] & 2 & 134 & 58 & 76 & -0.44 & -1.15 & 0.27 & $P=0.78$ & 0 \\
\hline [35] & 9 & 1944 & 713 & 1231 & -0.09 & -0.27 & 0.1 & $P=0.36$ & 74 \\
\hline [37] & 7 & 1045 & & & -0.2 & -0.42 & -0.02 & $P=0.07$ & 53 \\
\hline
\end{tabular}


Table 4 (continued)

\begin{tabular}{|c|c|c|c|c|c|c|c|c|c|}
\hline \multicolumn{10}{|c|}{ Oral intake (days) } \\
\hline & $n$ & n. of patients & RG & LG & WMD & $95 \% \mathrm{CI}$ & & $p$ value & $I^{2}(\%)$ \\
\hline [39] & 3 & 1611 & 477 & 1134 & -0.28 & -0.46 & -0.09 & $P=0.004$ & 0 \\
\hline [34] & 3 & 1611 & 477 & 1134 & -0.28 & -0.46 & -0.09 & $P<0.01$ & 0 \\
\hline [35] & 9 & 3151 & 2055 & 1096 & -0.23 & -0.34 & -0.13 & $P<0.0001$ & 0 \\
\hline \multicolumn{10}{|c|}{ Conversion rate } \\
\hline & $n$ & n. of patients & RG & LG & OR & $95 \% \mathrm{CI}$ & & $p$ value & $I^{2}(\%)$ \\
\hline [39] & 6 & 994 & 225 & 769 & 2.14 & 0.32 & 14.14 & $P=0.43$ & \\
\hline [23] & 4 & 1174 & 314 & 920 & 1.55 & 0.6 & 4.02 & $P=0.36$ & 17 \\
\hline [37] & 4 & 1231 & 365 & 866 & 1.58 & 0.6 & 4.14 & $P=0.35$ & 0 \\
\hline
\end{tabular}

Green are the meta-analyses that compares RG to LG and to Open Gastrectomy

\section{Primary outcomes}

\section{Operative time}

All selected meta-analyses report higher operative time for the robotic group compared to laparoscopy. A statistically significance reduction is reported in eleven studies [23, 33, 35-37, 39-41, 43-45]. It was an unsurprising result due to extra time for robotic docking and undocking as reported in literature [20].

\section{Intraoperative bleeding}

All studies report a reduction of intraoperative bleeding in the group of robotic gastrectomy compared to laparoscopic gastrectomy and only in three there is not a statistical significance $[34,41,45]$. This result could be explained with the operatory field magnification obtained with robotic threedimensional optic, associated with the higher precision in the small movements and the flapping filters of robotic system [46].

\section{Length of hospital stay}

Each meta-analysis report a small reduction in terms of hospital stay for patients who underwent robotic gastrectomy, except for Wang $\mathrm{Z}$ et al. [45] that report a negligible increase in hospitalization for RG groups. These results are strengthened by statistically significance only in three meta-analyses $[23,39,44]$.

\section{Number of harvested lymph nodes}

The number of harvested lymph nodes is a significant value for the oncological outcomes of gastrectomy: in 12 metaanalyses [23, 33-38, 40, 42-44] this number is higher for robotic technique and only in two studies $[41,45]$ is lower than laparoscopic gastrectomy. Only two meta-analyses show statistical significative results $[23,44]$ and report a higher number of harvested lymph nodes.

\section{Secondary outcomes}

\section{Overall complication rate}

Eleven meta-analyses [23, 34-38, 40-42, 44, 45] reported the incidence of overall complication after surgery and no significant difference between robotic and laparoscopic gastrectomy in terms of incidence of total complications was reported.

\section{Proximal and distal margin of resection}

Nine studies [23, 36-40, 42, 43, 45] analysed the difference between the length of proximal and distal margin of resection from the tumour: the proximal margin was more distant in patients with RG in seven studies[35-39, $42,44]$, in only one [41] the distance was substantially the same and in another one [23] it was higher in patients who underwent LG. Overall, these data does not show statistical significance. The distal margin was more distant in RG in five studies [36, 37, 39, 42, 44], in four [23, 35, 38, 41] the distance was higher in the LG: three studies [39, 42, 44] with statistical significance report an increased length of free distal margin of resection and only one [41] a reduction of this parameter.

\section{Mortality and morbidity}

Six meta-analyses [33, 35, 37-39, 43] report higher mortality rate in RG, while Hu LD et al. [23] report lower mortality, with no statistical significance. Only three studies report the morbidity rate after gastrectomy with conflicting results. Xiong et al. [33] outlined a lower morbidity in RG, while 
others $[39,43]$ found opposite results, with no statistical significance either way.

\section{Anastomotic leakage, anastomotic stenosis and intestinal obstruction}

Five studies report anastomotic leak rate: four papers [38, $39,41,43]$ indicate a higher incidence of anastomotic leakage in patients who underwent RG and one [44] a lower incidence. Three meta-analyses [38, 39, 41] outline a lower incidence of anastomotic stenosis and two [38, 39] a higher recurrence of intestinal occlusion. All these findings are not significant from a statistical point of view.

\section{Time to first flatus and oral intake}

Five meta-analyses $[23,34,35,37,39]$ investigate the time to first flatus and only three $[34,35,39]$ the time for the first oral intake after surgery: all the studies indicate a shorter recovery of bowel function in patient underwent to RG and, of these, one [23] is statistically significant for time to flatus and all $[34,35,39]$ are such for time to oral intake.

\section{Conversion to open surgery}

The risk of conversion to open surgery is higher in RG for all three studies $[23,37,39]$ that investigate this issue. Nevertheless no statistical significance is reported.

\section{Stratification of evidence}

Based on the previously reported classification method we obtained three different levels of evidence for each outcome analysed in the review: only the oral intake is supported by suggestive evidence, operation time and blood loss are supported by weak evidence and the other outcomes are classified as non-significant (Table 5).

\section{Discussion}

\section{Main findings and interpretation in light of existing evidence}

In this umbrella review of systematic reviews and meta-analyses evaluating the current evidence for potential benefits and harm associated with robotic gastrectomy compared to laparoscopic gastrectomy for gastric cancer, we summarized 14 studies covering overall 146 primary studies, and more than 37,500 subjects. Our assessment did not show an overall excess of findings with significant results, by contrast with other medical specialties, in which an excess of significant results is reported [47-49]. In our study, a large proportion of the examined meta-analyses had a not large heterogeneity and some studies had a large heterogeneity.

The applied Egger test is particularly difficult to interpret when between-study heterogeneity is large. Heterogeneity might often be a manifestation of bias in some studies of a meta-analysis, but could also emerges from genuine differences across studies. Some reasons for heterogeneity include the mixture of cohort studies and case-control studies in some of the meta-analyses, differences in the populations analyzed, in the reproducibility of the surgical technique and in the stage of gastric cancer.

The outcomes reported for each surgical technique need to be interpreted with caution, in particular for the metaanalyses in which the heterogeneity is large, the number of studies is relatively small, the largest study is more conservative than the summary effect.

According to statistical data analyses, robotic gastrectomy is associated with shorter time to oral intake with a high level of evidence. The data regarding lesser intraoperative bleeding and longer operation time for robotic approach are supported by weak evidence. On the other hand, the data regarding other outcomes are insufficient as well as nonsignificant, from an evidence point of view, to draw any robust conclusion.

As observed in each selected meta-analysis, intraoperative blood loss was significantly lesser in the RG than in the LG groups. From a theoretical point of view, robotic procedure is a more precise technique that could help surgeons visualize small vessels. Furthermore, the robotic arms are more stable than a surgeon's hands, leading to a significant reduction of musculoskeletal fatigue and physiologic tremor over time in surgeons [36]. In addition, the improved dexterity of an internal articulated wrist provides greater flexibility in a restricted operative field, and the stereoscopic vision enables surgeons to effectively minimize the risk of tissue and blood vessel injuries and intraoperative bleeding as well. In the end, we found strong evidence for intraoperative bleeding, shedding light on this benefit of robotic gastrectomy when compared with LG.

Thirteen studies showed that the hospital stay in the RG groups was negligibly shorter (nearly a day) than that in the LG groups, reaching statistical significance in only three meta-analyses. Similarly, other potential factors that should have an important impact on postoperative recovery, such as time to diet and first flatus resulted shorter in RG groups. 
Table 5 Stratification of evidence

\begin{tabular}{|c|c|c|c|c|c|c|}
\hline & $\begin{array}{l}\text { Sample size (num- } \\
\text { ber of cases) }\end{array}$ & $\begin{array}{l}\text { Significance thresh- } \\
\text { old reached (under } \\
\text { the random-effects } \\
\text { model) }\end{array}$ & $\begin{array}{l}95 \% \text { prediction } \\
\text { interval rule }\end{array}$ & $\begin{array}{l}\text { Estimate of } \\
\text { heterogene- } \\
\text { ity }\end{array}$ & $\begin{array}{l}\text { Small-study effects } \\
\text { or excess signifi- } \\
\text { cance bias }\end{array}$ & $\begin{array}{l}\text { Random-effects } \\
\text { summary effect size } \\
(95 \% \mathrm{CI})\end{array}$ \\
\hline & $\begin{array}{l}\text { Results supported } \\
\text { by suggestive } \\
\text { evidence }\end{array}$ & & & & & \\
\hline \multirow[t]{2}{*}{ Oral intake[34] } & $>1000$ & $<0.001$ & $\begin{array}{l}\text { Including the null } \\
\text { value }\end{array}$ & not large & Neither & $0.39(0.23 / 0.61)$ \\
\hline & $\begin{array}{l}\text { Results supported } \\
\text { by weak evidence }\end{array}$ & & & & & \\
\hline Operation time[34] & $>1000$ & $<0.05$ but $>0.001$ & $\begin{array}{l}\text { Including the null } \\
\text { value }\end{array}$ & very large & Neither & $0.88(0.72 / 1.05)$ \\
\hline \multirow[t]{2}{*}{ Blood loss[34] } & $>1000$ & $<0.05$ but $>0.001$ & $\begin{array}{l}\text { Including the null } \\
\text { value }\end{array}$ & very large & Neither & $0.44(0.65 / 2.41)$ \\
\hline & $\begin{array}{l}\text { Non significant } \\
\text { Results }\end{array}$ & & & & & \\
\hline $\begin{array}{l}\text { Harvested limpho- } \\
\text { nodes[34] }\end{array}$ & $>1000$ & $>0.05$ & $\begin{array}{l}\text { Including the null } \\
\text { value }\end{array}$ & very large & Neither & $2.60(0.66 / 5.90)$ \\
\hline Hospital Stay[34] & $>1000$ & $>0.05$ & $\begin{array}{l}\text { Including the null } \\
\text { value }\end{array}$ & very large & Neither & $0.63(0.45 / 0.95)$ \\
\hline $\begin{array}{l}\text { Total complica- } \\
\text { tions [34] }\end{array}$ & $>1000$ & $>0.05$ & $\begin{array}{l}\text { Including the null } \\
\text { value }\end{array}$ & not large & Neither & $1.05(0.88 / 1.26)$ \\
\hline $\begin{array}{l}\text { Prossimal Mar- } \\
\text { gins[34] }\end{array}$ & $>1000$ & $>0.05$ & $\begin{array}{l}\text { Including the null } \\
\text { value }\end{array}$ & not large & Neither & $0.25(0.12 / 0.65)$ \\
\hline Distal Margins[34] & $>1000$ & $>0.05$ & $\begin{array}{l}\text { Including the null } \\
\text { value }\end{array}$ & very large & Neither & $0.16(0.10 / 0.83)$ \\
\hline Mortality[34] & $>1000$ & $>0.05$ & $\begin{array}{l}\text { Including the null } \\
\text { value }\end{array}$ & not large & Neither & $1.62(0.62 / 4.2)$ \\
\hline Morbidity[42] & $>1000$ & $>0.05$ & $\begin{array}{l}\text { Including the null } \\
\text { value }\end{array}$ & not large & Neither & $1.36(0.38 / 4.88)$ \\
\hline $\begin{array}{l}\text { Anastomotic Leak- } \\
\text { age[42] }\end{array}$ & $>1000$ & $>0.05$ & $\begin{array}{l}\text { Including the null } \\
\text { value }\end{array}$ & not large & Neither & $1.16(0.68 / 1.96)$ \\
\hline $\begin{array}{l}\text { Anastomotic Steno- } \\
\operatorname{sis}[40]\end{array}$ & $>1000$ & $>0.05$ & $\begin{array}{l}\text { Including the null } \\
\text { value }\end{array}$ & not large & Neither & $0.9(0.29 / 2.77)$ \\
\hline $\begin{array}{l}\text { Intestinal Obstruc- } \\
\text { tion[38] }\end{array}$ & $>1000$ & $>0.05$ & $\begin{array}{l}\text { Including the null } \\
\text { value }\end{array}$ & not large & Neither & $1.64(0.43 / 2.53)$ \\
\hline $\begin{array}{l}\text { Time to first fla- } \\
\text { tus[34] }\end{array}$ & $>1000$ & $>0.05$ & $\begin{array}{l}\text { Including the null } \\
\text { value }\end{array}$ & very large & Neither & $0.16(0.03 / 0.18)$ \\
\hline Conversion rate[36] & $>1000$ & $>0.05$ & $\begin{array}{l}\text { Including the null } \\
\text { value }\end{array}$ & not large & Neither & $1.58(0.6 / 4.14)$ \\
\hline
\end{tabular}

Based on these results, we postulate that the faster recovery of patients receiving robotic approach induced the different postoperative hospital stay between the 2 groups. The evidence from our study is highly suggestive for these benefits; therefore, surgeons and policy makers should consider the robotic approach as an acceptable option in treating gastric cancer.

As prognostic factors of surgical therapy from an oncological point of view, the number of resected lymph nodes as well as the length of resection margins cannot be ignored. In 
our umbrella review, even if the number of retrieved nodes obtained with the robotic gastrectomy was higher, the significance was negatively affected by the low value of evidence stratification. Several studies [23, 33-38, 40, 42-44] report that the number of retrieved lymph nodes during extra-perigastric lymphadenectomy, especially in the case of splenic pedicle and splenic hilum and in the supra-pancreatic areas, was significantly higher for the robotic group compared to the laparoscopy group. However, it appears clear that the operative steps of lymph node dissection robotically performed are generally the same as those in laparoscopy. We could postulate that the traditional straight laparoscopic instruments fail to help surgeons reach deep-seated vessels and such nodal areas. In addition, the tremor filtering, wristed instruments, as well as stable exposure and highresolution image enable surgeons to execute thoroughly surgical maneuvres thoroughly [50]. However, most of the primary studies included patients who underwent both subtotal gastrectomy and total gastrectomy without distinction, and the stage of gastric cancer was also not the same for all of the enrolled patients. Anyway, since case-matching studies according to the type of gastrectomy and the extension of lymphadenectomy comparing robotic and laparoscopic approach are needed to reduce the bias, given that only two out of 12 meta-analyses reached statistical significance, surgeons and policy makers should cautiously consider the marginal superiority of robotic gastrectomy in lymph-node retrieval. In addition, evidence for difference in margins between robotic and laparoscopic groups is only suggestive. As a pathological parameter, the proximal margin was longer in the RG group, while distal margin resulted in controversial results between the two groups. These findings may open up new research directions.

The prolonged operating time in RG was shown in all the included meta-analyses, preluding a negative impact on postoperative outcomes due to prolonged exposure time to pneumoperitoneum and the associated increased anesthesia time. However, previous studies investigating the effect of longer operation time in patients receiving laparoscopic gastrectomy did not show detrimental surgical results [35]. One of the most important reasons of prolonged time is that robotic gastrectomy requires "setting and docking" time for the robot, which inevitably results in a longer operative time requiring almost $30 \mathrm{~min}$ of extra time [51-54]. In addition, the learning curve for robotic gastrectomy significantly affect the time spent during surgery. Eom BW et al. [21] stated that intervention time was reduced after at least 15 robotic gastrectomies. On the same way, Woo JH et al. [24] demonstrated a reduction of the mean operative time from 233 to 219 min after the execution of 100 cases. Anyway, considering the development of the robotic surgery systems, more experience, and a shortened learning curve, we can postulate that RG is technically feasible in regard to operation time.

Interestingly, the prolonged operation time of RG was not associated to any increase in postoperative complications, mortality, or conversion rate. It is postulated that technical advantages such as 3D vision and tremor filtering could contribute to safer implementations of the robotic system for gastric surgery [21, 47].

Due to limited meta-analyses included, an umbrella review for cost evaluation was not performed. But Hyun et al. [41] and Chen et al. [35] report that the RG costs an average of $€ 3,189$ and 3900 USD, respectively, compared to the LG, of which most of this amount, around $€ 2831$ is determined from the DaVinci robotic system itself. On the basis of what was reported by both authors, the possible advantages of the robotic approach would not be justified by the higher cost but looking at the set of costs related to hospitalization, we come to the conclusion that the higher operating costs are finally offset by the reduction of complications and of hospitalization time.

The results from primary studies are consistent with the findings of our umbrella review as we found highly suggestive evidence that RG and LG are equivalent as regard the safety and feasibility, considering the robotic approach as a safe and non-inferior option in treating gastric cancer toward LG.

\section{Strengths and limitations}

We performed this detailed umbrella review to assess the benefits and harm of robotic gastrectomy compared with laparoscopic approach. In addition, we used a comprehensive and systematic criterion to grade evidence levels to rate the strength of these systematic reviews and meta-analyses. Our review inevitably has limitations and drawbacks. First, we fully trust the accuracy of the data provided in the included 
meta-analyses. As such, problems within the published data may impact the evidence-rating results despite our analyses. All the meta-analyses included in this review compared retrospective non-randomized studies and until now no randomized clinical trials (RCTs) are available between RG and LG. Another limitation is that significant heterogeneity was recognized in some characteristics of the primary studies. Several papers included patients who underwent both subtotal gastrectomy and total gastrectomy without distinction. The stage of gastric cancer was also not the same for all of the enrolled patients. The majority of the studies were from Eastern populations, whereas the minority were from Europe. The classification of evidence supporting the single outcome highlighted how no outcomes analysed in the creation of this review are supported by convincing or highly suggestive evidence.

On the other hand, we are convinced of the strength of our umbrella review, since the methodological quality of all included systematic reviews and meta-analyses were considered critically high.

\section{Conclusions}

In conclusion, the safety and efficacy of robotic gastrectomy are not clearly supported by strong evidence, suggesting that the outcomes reported for each surgical technique need to be interpreted with caution, in particular for the meta-analyses in which the heterogeneity is large. Certainly, robotic gastrectomy is associated with shorter time to oral intake, lesser intraoperative bleeding and longer operation time with an acceptable level of evidence. On the other hand, the data regarding other outcomes are insufficient as well as nonsignificant, from an evidence point of view, to draw any robust conclusion.

\section{Appendix 1: PRISMA checklist}

\begin{tabular}{|c|c|c|c|}
\hline Section/topic & \# & Checklist item & Reported on page \# \\
\hline \multicolumn{4}{|l|}{ Title } \\
\hline Title & 1 & Identify the report as a systematic review, meta-analysis, or both & 1 \\
\hline \multicolumn{4}{|l|}{ Abstract } \\
\hline Structured summary & 2 & $\begin{array}{l}\text { Provide a structured summary including, as applicable: background; objectives; data } \\
\text { sources; study eligibility criteria, participants, and interventions; study appraisal and } \\
\text { synthesis methods; results; limitations; conclusions and implications of key findings; } \\
\text { systematic review registration number }\end{array}$ & 2 \\
\hline \multicolumn{4}{|l|}{ Introduction } \\
\hline Rationale & 3 & Describe the rationale for the review in the context of what is already known & 3 \\
\hline Objectives & 4 & $\begin{array}{l}\text { Provide an explicit statement of questions being addressed with reference to partici- } \\
\text { pants, interventions, comparisons, outcomes, and study design (PICOS) }\end{array}$ & 3 \\
\hline \multicolumn{4}{|l|}{ Methods } \\
\hline Protocol and registration & 5 & $\begin{array}{l}\text { Indicate if a review protocol exists, if and where it can be accessed (e.g., Web address), } \\
\text { and, if available, provide registration information including registration number }\end{array}$ & 4 \\
\hline Eligibility criteria & 6 & $\begin{array}{l}\text { Specify study characteristics (e.g., PICOS, length of follow-up) and report characteris- } \\
\text { tics (e.g., years considered, language, publication status) used as criteria for eligibil- } \\
\text { ity, giving rationale }\end{array}$ & Into Protocol \\
\hline Information sources & 7 & $\begin{array}{l}\text { Describe all information sources (e.g., databases with dates of coverage, contact with } \\
\text { study authors to identify additional studies) in the search and date last searched }\end{array}$ & 4 \\
\hline Search & 8 & $\begin{array}{l}\text { Present full electronic search strategy for at least one database, including any limits } \\
\text { used, such that it could be repeated }\end{array}$ & 4 \\
\hline Study selection & 9 & $\begin{array}{l}\text { State the process for selecting studies (i.e., screening, eligibility, included in systematic } \\
\text { review, and, if applicable, included in the meta-analysis) }\end{array}$ & 4 \\
\hline Data collection process & 10 & $\begin{array}{l}\text { Describe method of data extraction from reports (e.g., piloted forms, independently, in } \\
\text { duplicate) and any processes for obtaining and confirming data from investigators }\end{array}$ & 4 \\
\hline Data items & 11 & $\begin{array}{l}\text { List and define all variables for which data were sought (e.g., PICOS, funding sources) } \\
\text { and any assumptions and simplifications made }\end{array}$ & Into Protocol \\
\hline
\end{tabular}




\begin{tabular}{|c|c|c|c|}
\hline Section/topic & \# & Checklist item & Reported on page \# \\
\hline $\begin{array}{l}\text { Risk of bias in individual } \\
\text { studies }\end{array}$ & 12 & $\begin{array}{l}\text { Describe methods used for assessing risk of bias of individual studies (including } \\
\text { specification of whether this was done at the study or outcome level), and how this } \\
\text { information is to be used in any data synthesis }\end{array}$ & 4 \\
\hline Summary measures & 13 & State the principal summary measures (e.g., risk ratio, difference in means) & 6 \\
\hline Synthesis of results & 14 & $\begin{array}{l}\text { Describe the methods of handling data and combining results of studies, if done, } \\
\text { including measures of consistency }\left(\text { e.g., } \mathrm{I}^{2}\right) \text { for each meta-analysis }\end{array}$ & 6 \\
\hline $\begin{array}{l}\text { Risk of bias across } \\
\text { studies }\end{array}$ & 15 & $\begin{array}{l}\text { Specify any assessment of risk of bias that may affect the cumulative evidence (e.g., } \\
\text { publication bias, selective reporting within studies) }\end{array}$ & \\
\hline Additional analyses & 16 & $\begin{array}{l}\text { Describe methods of additional analyses (e.g., sensitivity or subgroup analyses, meta- } \\
\text { regression), if done, indicating which were pre-specified }\end{array}$ & \\
\hline \multicolumn{4}{|l|}{ Results } \\
\hline Study selection & 17 & $\begin{array}{l}\text { Give numbers of studies screened, assessed for eligibility, and included in the review, } \\
\text { with reasons for exclusions at each stage, ideally with a flow diagram }\end{array}$ & 5 \\
\hline Study characteristics & 18 & $\begin{array}{l}\text { For each study, present characteristics for which data were extracted (e.g., study size, } \\
\text { PICOS, follow-up period) and provide the citations }\end{array}$ & 5 \\
\hline $\begin{array}{l}\text { Risk of bias within } \\
\text { studies }\end{array}$ & 19 & $\begin{array}{l}\text { Present data on risk of bias of each study and, if available, any outcome level assess- } \\
\text { ment (see item 12) }\end{array}$ & \\
\hline $\begin{array}{l}\text { Results of individual } \\
\text { studies }\end{array}$ & 20 & $\begin{array}{l}\text { For all outcomes considered (benefits or harms), present, for each study: (a) simple } \\
\text { summary data for each intervention group (b) effect estimates and confidence inter- } \\
\text { vals, ideally with a forest plot }\end{array}$ & 6 \\
\hline Synthesis of results & 21 & $\begin{array}{l}\text { Present results of each meta-analysis done, including confidence intervals and measures } \\
\text { of consistency }\end{array}$ & $5-6-7$ \\
\hline $\begin{array}{l}\text { Risk of bias across } \\
\text { studies }\end{array}$ & 22 & Present results of any assessment of risk of bias across studies (see Item 15) & \\
\hline Additional analysis & 23 & $\begin{array}{l}\text { Give results of additional analyses, if done (e.g., sensitivity or subgroup analyses, } \\
\text { meta-regression [see Item 16]) }\end{array}$ & \\
\hline \multicolumn{4}{|l|}{ Discussion } \\
\hline Summary of evidence & 24 & $\begin{array}{l}\text { Summarize the main findings including the strength of evidence for each main out- } \\
\text { come; consider their relevance to key groups (e.g., healthcare providers, users, and } \\
\text { policy makers) }\end{array}$ & 9 \\
\hline Limitations & 25 & $\begin{array}{l}\text { Discuss limitations at study and outcome level (e.g., risk of bias), and at review-level } \\
\text { (e.g., incomplete retrieval of identified research, reporting bias) }\end{array}$ & 10 \\
\hline Conclusions & 26 & $\begin{array}{l}\text { Provide a general interpretation of the results in the context of other evidence, and } \\
\text { implications for future research }\end{array}$ & 11 \\
\hline \multicolumn{4}{|l|}{ Funding } \\
\hline Funding & 27 & $\begin{array}{l}\text { Describe sources of funding for the systematic review and other support (e.g., supply of } \\
\text { data); role of funders for the systematic review }\end{array}$ & 1 \\
\hline
\end{tabular}

From: Moher D, Liberati A, Tetzlaff J, Altman DG, The PRISMA Group (2009). Preferred Reporting Items for Systematic Reviews and MetaAnalyses: The PRISMA Statement. PLoS Med 6(7): e1000097. https://doi.org/10.1371/journal.pmed1000097

For more information, visit: www.prisma-statement.org. 


\section{Appendix 2: flow diagram}

PRISMA 2009 Flow Diagram

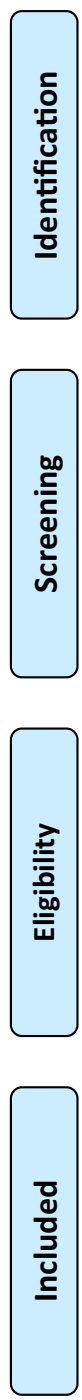

Records identified through database searching $(n=149)$
Additional records identified through other sources $(n=7)$

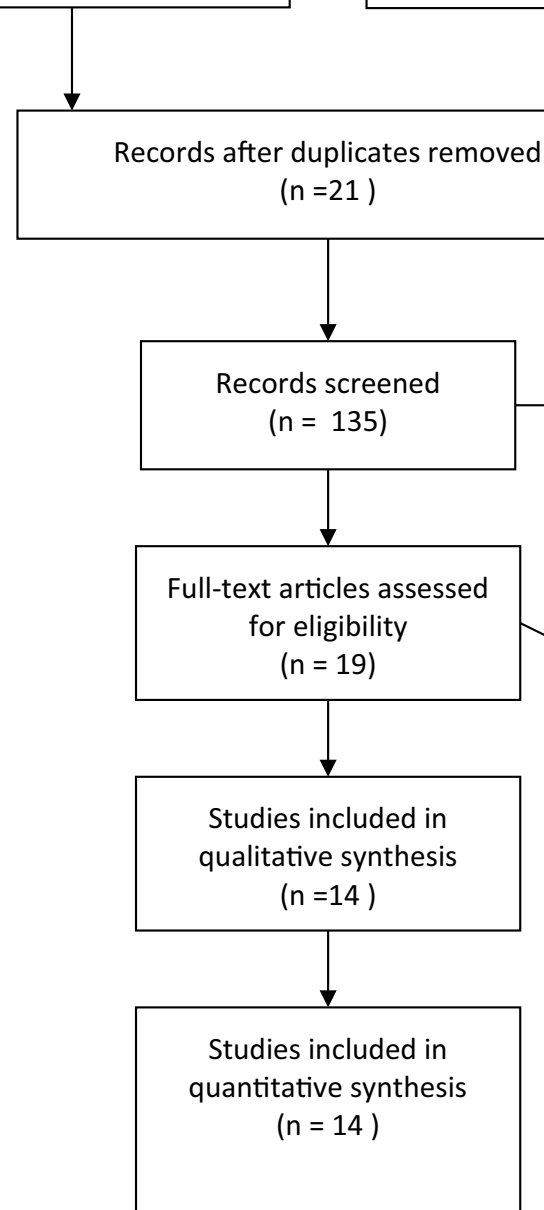

Records excluded (n 116)

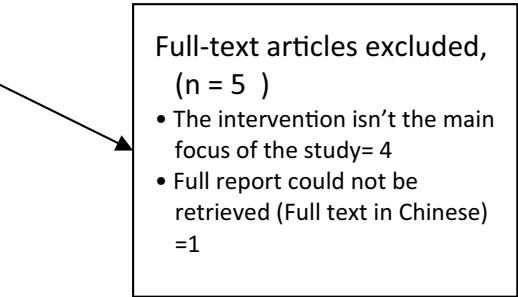
$(n=14)$ Analyses: The PRISMA Statement. PLoS Med 6(7): e1000097. doi:10.1371/journal.pmed1000097

For more information, visit www.prisma-statement.org. 


\section{Appendix 3: List of included meta-analyses}

See references [23, 33-45].

Author contributions Contributors LM and FR conceived the study. LM and DF effected search strategy, study selection, data extraction and data analysis. LM drafted the manuscript. VS, DM and FR revised the manuscript for important intellectual content; and contributed to the methodology. FR is the clinical lead and DM is the guarantor of the review.

Funding Open access funding provided by Università degli Studi di Siena within the CRUI-CARE Agreement.. This research received no specific grant from any funding agency in the public, commercial or not for-profit sectors.

\section{Declarations}

Conflict of interest The authors declare there is no conflict of interest or financial ties to disclose.

Research involving human participants and/or animals This research did not involve human participants and/or animals, since it is a secondary research.

Informed consent Not applicable.

Open Access This article is licensed under a Creative Commons Attribution 4.0 International License, which permits use, sharing, adaptation, distribution and reproduction in any medium or format, as long as you give appropriate credit to the original author(s) and the source, provide a link to the Creative Commons licence, and indicate if changes were made. The images or other third party material in this article are included in the article's Creative Commons licence, unless indicated otherwise in a credit line to the material. If material is not included in the article's Creative Commons licence and your intended use is not permitted by statutory regulation or exceeds the permitted use, you will need to obtain permission directly from the copyright holder. To view a copy of this licence, visit http://creativecommons.org/licenses/by/4.0/.

\section{References}

1. Wu HL, Tian Q, Peng CW et al (2011) Multivariate survival and outcome analysis of 154 patients with gastric cancer at a single Chinese institution. Asian Pac J Cancer Prev 12:3341-3345

2. Marano L, Marrelli D, Roviello F (2016) Focus on research: nodal dissection for gastric cancer-a dilemma worthy of King Solomon! Eur J Surg Oncol 42:1623-1624

3. Kim H-H, Hyung WJ, Cho GS et al (2010) Morbidity and mortality of laparoscopic gastrectomy versus open gastrectomy for gastric cancer. Ann Surg 251:417-420. https://doi.org/10.1097/ SLA.0b013e3181cc8f6b

4. Katai H, Sasako M, Fukuda $\mathrm{H}$ et al (2010) Safety and feasibility of laparoscopy-assisted distal gastrectomy with suprapancreatic nodal dissection for clinical stage I gastric cancer: a multicenter phase II trial (JCOG 0703). Gastric Cancer 13:238-244. https:// doi.org/10.1007/s10120-010-0565-0

5. Kim H-H, Han S-U, Kim M-C et al (2014) Long-term results of laparoscopic gastrectomy for gastric cancer: a large-scale case-control and case-matched korean multicenter study. J Clin Oncol 32:627-633. https://doi.org/10.1200/JCO.2013.48.8551

6. Ohtani H, Tamamori Y, Noguchi K et al (2010) A meta-analysis of randomized controlled trials that compared laparoscopy-assisted and open distal gastrectomy for early gastric cancer. J Gastrointest Surg 14:958-964. https://doi.org/10.1007/s11605-010-1195-x

7. Kitano S, Shiraishi N, Fujii K et al (2002) A randomized controlled trial comparing open vs laparoscopy-assisted distal gastrectomy for the treatment of early gastric cancer: an interim report. Surgery 131:S306-S311

8. Hayashi H, Ochiai T, Shimada H, Gunji Y (2005) Prospective randomized study of open versus laparoscopy-assisted distal gastrectomy with extraperigastric lymph node dissection for early gastric cancer. Surg Endosc 19:1172-1176. https://doi.org/10. 1007/s00464-004-8207-4

9. Kim Y-W, Baik YH, Yun YH et al (2008) Improved quality of life outcomes after laparoscopy-assisted distal gastrectomy for early gastric cancer. Ann Surg 248:721-727. https://doi.org/10.1097/ SLA.0b013e318185e62e

10. Ding J, Liao G-Q, Liu H-L et al (2012) Meta-analysis of laparoscopy-assisted distal gastrectomy with D2 lymph node dissection for gastric cancer. J Surg Oncol 105:297-303. https://doi.org/10. 1002/jso. 22098

11. Kodera Y, Fujiwara M, Ohashi N et al (2010) Laparoscopic surgery for gastric cancer: a collective review with meta-analysis of randomized trials. J Am Coll Surg 211:677-686. https://doi.org/ 10.1016/j.jamcollsurg.2010.07.013

12. Degiuli M, De Manzoni G, Di Leo A et al (2016) Gastric cancer: current status of lymph node dissection. World J Gastroenterol 22:2875-2893

13. Pan JH, Zhou H, Zhao X, xu, et al (2017) Long-term oncological outcomes in robotic gastrectomy versus laparoscopic gastrectomy for gastric cancer: a meta-analysis. Surg Endosc 31:4244-4251. https://doi.org/10.1007/s00464-017-5891-4

14. Zhou D, Quan Z, Wang J et al (2014) Laparoscopic-assisted versus open distal gastrectomy with $\mathrm{D} 2$ lymph node resection for advanced gastric cancer: effect of learning curve on shortterm outcomes. a meta-analysis. J Laparoendosc Adv Surg Tech 24:139-150. https://doi.org/10.1089/lap.2013.0481

15. Hashizume M, Sugimachi K (2003) Robot-assisted gastric surgery. Surg Clin N Am 83:1429-1444. https://doi.org/10.1016/S00396109(03)00158-0

16. Hashizume M, Shimada M, Tomikawa M et al (2002) Early experiences of endoscopic procedures in general surgery assisted by a computer-enhanced surgical system. Surg Endosc Other Interv Tech. https://doi.org/10.1007/s004640080154

17. Son T, Lee JH, Kim YM et al (2014) Robotic spleen-preserving total gastrectomy for gastric cancer: comparison with conventional laparoscopic procedure. Surg Endosc 28:2606-2615. https://doi. org/10.1007/s00464-014-3511-0

18. Suda K, Man-I M, Ishida Y et al (2015) Potential advantages of robotic radical gastrectomy for gastric adenocarcinoma in comparison with conventional laparoscopic approach: a single institutional retrospective comparative cohort study. Surg Endosc 29:673-685. https://doi.org/10.1007/s00464-014-3718-0

19. Viñuela EF, Gonen M, Brennan MF et al (2012) Laparoscopic versus open distal gastrectomy for gastric cancer: a meta-analysis of randomized controlled trials and high-quality nonrandomized studies. Ann Surg 255:446-456. https://doi.org/10.1097/SLA. 0b013e31824682f4

20. Kang BH, Xuan Y, Hur H et al (2012) Comparison of surgical outcomes between robotic and laparoscopic gastrectomy for gastric cancer: the learning curve of robotic surgery. J Gastric Cancer 12:156-163. https://doi.org/10.5230/jgc.2012.12.3.156

21. Eom BW, Yoon HM, Ryu KW et al (2012) Comparison of surgical performance and short-term clinical outcomes between 
laparoscopic and robotic surgery in distal gastric cancer. Eur $\mathbf{J}$ Surg Oncol 38:57-63. https://doi.org/10.1016/j.ejso.2011.09.006

22. Roviello G, Petrioli R, Marano L et al (2016) Angiogenesis inhibitors in gastric and gastroesophageal junction cancer. Gastric Cancer 19:31-41. https://doi.org/10.1007/s10120-015-0537-5

23. Hu L-D, Li X-F, Wang X-Y, Guo T-K (2016) Robotic versus laparoscopic gastrectomy for gastric carcinoma: a meta-analysis of efficacy and safety. Asian Pac J Cancer Prev 17:4327-4333

24. Hyung WJ (2007) Robotic surgery in gastrointestinal surgery. Korean J Gastroenterol 50:256-259

25. Baek S-J, Lee D-W, Park S-S, Kim S-H (2011) Current status of robot-assisted gastric surgery. World J Gastrointest Oncol 3:137143. https://doi.org/10.4251/wjgo.v3.i10.137

26. Buchs NC, Bucher P, Pugin F, Morel P (2011) Robot-assisted gastrectomy for cancer. Minerva Gastroenterol Dietol 57:33-42

27. Marano L, Fusario D, Savelli V et al (2020) Robotic versus laparoscopic gastrectomy for gastric cancer: protocol for umbrella review of systematic reviews and meta-analyses. BMJ Open 10:e033634. https://doi.org/10.1136/bmjopen-2019-033634

28. Aromataris E, Fernandez R, Godfrey CM et al (2015) Summarizing systematic reviews. Int J Evid Based Healthc 13:132-140. https://doi.org/10.1097/XEB.0000000000000055

29. Moher D, Liberati A, Tetzlaff J et al (2010) Preferred reporting items for systematic reviews and meta-analyses: the PRISMA statement. Int J Surg 8:336-341. https://doi.org/10.1016/j.ijsu. 2010.02.007

30. Shea BJ, Reeves BC, Wells G et al (2017) AMSTAR 2: a critical appraisal tool for systematic reviews that include randomised or non-randomised studies of healthcare interventions, or both. BMJ 358:j4008. https://doi.org/10.1136/bmj.j4008

31. Chinn S (2000) A simple method for converting an odds ratio to effect size for use in meta-analysis. Stat Med 19:3127-3131. https://doi.org/10.1002/1097-0258(20001130)19:22\%3c3127:: AID-SIM784\%3e3.0.CO;2-M

32. Egger M, Smith GD, Schneider M, Minder C (1997) Bias in metaanalysis detected by a simple, graphical test. Br Med J 315:629_ 634. https://doi.org/10.1136/bmj.315.7109.629

33. Xiong B, Ma L, Zhang C (2012) Robotic versus laparoscopic gastrectomy for gastric cancer: a meta-analysis of short outcomes. Surg Oncol 21:274-280. https://doi.org/10.1016/j.suronc.2012.05.004

34. Duan BS, Zhao J, Xie LF, Wang Y (2017) Robotic verse laparoscopic gastrectomy for gastric cancer: a pooled analysis of 11 individual studies. Surg Laparosc Endosc Percutaneous Tech 27:147-153

35. Chen K, Pan Y, Zhang B et al (2017) Robotic versus laparoscopic gastrectomy for gastric cancer: a systematic review and updated meta-analysis. BMC Surg 17:1-14. https://doi.org/10.1186/ s12893-017-0290-2

36. Wang Y, Zhao X, Song Y et al (2017) A systematic review and meta-analysis of robot-assisted versus laparoscopically assisted gastrectomy for gastric cancer. Med (United States). https://doi. org/10.1097/MD.0000000000008797

37. Bobo Z, Xin W, Jiang L et al (2019) Robotic gastrectomy versus laparoscopic gastrectomy for gastric cancer: meta-analysis and trial sequential analysis of prospective observational studies. Surg Endosc 33:1033-1048. https://doi.org/10.1007/ s00464-018-06648-z

38. Liao GX, Xie GZ, Li R et al (2013) Meta-analysis of outcomes compared between robotic and laparoscopic gastrectomy for gastric cancer. Asian Pac J Cancer Prev 14:4871-4875. https://doi. org/10.7314/APJCP.2013.14.8.4871

39. Xiong J, Nunes QM, Tan C et al (2013) Comparison of shortterm clinical outcomes between robotic and laparoscopic gastrectomy for gastric cancer: a meta-analysis of 2495 patients. J
Laparoendosc Adv Surg Tech 23:965-976. https://doi.org/10. 1089/lap.2013.0279

40. Marano A, Young Choi Y, Hyung WJ et al (2013) Robotic versus laparoscopic versus open gastrectomy: a meta-analysis. J Gastric Cancer 13:136-148. https://doi.org/10.5230/jgc.2013.13.3.136

41. Hyun MH, Lee CH, Kim HJ et al (2013) Systematic review and meta-analysis of robotic surgery compared with conventional laparoscopic and open resections for gastric carcinoma. Br J Surg 100:1566-1578. https://doi.org/10.1002/bjs.9242

42. Shen WS, Xi HQ, Chen L, Wei B (2014) A meta-analysis of robotic versus laparoscopic gastrectomy for gastric cancer. Surg Endosc 28:2795-2802. https://doi.org/10.1007/ s00464-014-3547-1

43. Zong L, Seto Y, Aikou S, Takahashi T (2014) Efficacy evaluation of subtotal and total gastrectomies in robotic surgery for gastric cancer compared with that in open and laparoscopic resections: a meta-analysis. PLoS ONE. https://doi.org/10.1371/journal.pone. 0103312

44. Chuan L, Yan S, Pei-Wu Y (2015) Meta-analysis of the short-term outcomes of robotic-assisted compared to laparoscopic gastrectomy. Minim Invasive Ther Allied Technol 24:127-134. https:// doi.org/10.3109/13645706.2014.985685

45. Wang Z, Wang Y, Liu Y (2017) Comparison of short outcomes between laparoscopic and experienced robotic gastrectomy: a meta-analysis and systematic review. J Minim Access Surg 13:1. https://doi.org/10.4103/0972-9941.182653

46. Tsai S-H, Liu C-A, Huang K-H et al (2017) Advances in laparoscopic and robotic gastrectomy for gastric cancer. Pathol Oncol Res 23:13-17. https://doi.org/10.1007/s12253-016-0131-0

47. Tsilidis KK, Papatheodorou SI, Evangelou E, Ioannidis JPA (2012) Evaluation of excess statistical significance in meta-analyses of 98 biomarker associations with cancer risk. J Natl Cancer Inst 104:1867-1878. https://doi.org/10.1093/jnci/djs437

48. Tsilidis KK, Panagiotou OA, Sena ES et al (2013) Evaluation of excess significance bias in animal studies of neurological diseases. PLoS Biol 11:e1001609. https://doi.org/10.1371/journal. pbio.1001609

49. Tzoulaki I, Siontis KC, Evangelou E, Ioannidis JPA (2013) Bias in associations of emerging biomarkers with cardiovascular disease. JAMA Intern Med 173:664-671. https://doi.org/10.1001/ jamainternmed.2013.3018

50. Kim Y-W, Reim D, Park JY et al (2016) Role of robot-assisted distal gastrectomy compared to laparoscopy-assisted distal gastrectomy in suprapancreatic nodal dissection for gastric cancer. Surg Endosc 30:1547-1552. https://doi.org/10.1007/ s00464-015-4372-x

51. deSouza AL, Prasad LM, Park JJ et al (2010) Robotic assistance in right hemicolectomy: is there a role? Dis Colon Rectum 53:1000 1006. https://doi.org/10.1007/DCR.0b013e3181d32096

52. Berber E, Akyildiz HY, Aucejo F et al (2010) Robotic versus laparoscopic resection of liver tumours. HPB 12:583-586. https:// doi.org/10.1111/j.1477-2574.2010.00234.x

53. Ceccarelli G, Marano L, Codacci-Pisanelli M et al (2018) A new robot-assisted Billroth-I reconstruction: details of the technique and early results. Surg Laparosc Endosc Percutaneous Tech. https://doi.org/10.1097/SLE.0000000000000505

54. Cestari A, Ferrari M, Zanoni M et al (2015) Side docking of the da Vinci robotic system for radical prostatectomy: advantages over traditional docking. J Robot Surg 9:243-247. https://doi.org/10. 1007/s11701-015-0523-2

Publisher's Note Springer Nature remains neutral with regard to jurisdictional claims in published maps and institutional affiliations. 